\title{
Long-term consequences of an intensive care unit stay in older critically ill patients: design of a longitudinal study
}

Marie-Madlen Jeitziner ${ }^{1,4^{*}}$, Virpi Hantikainen ${ }^{2}$, Antoinette Conca ${ }^{3}$ and Jan PH Hamers ${ }^{4}$

\begin{abstract}
Background: Modern methods in intensive care medicine often enable the survival of older critically ill patients. The short-term outcomes for patients treated in intensive care units (ICUs), such as survival to hospital discharge, are well documented. However, relatively little is known about subsequent long-term outcomes. Pain, anxiety and agitation are important stress factors for many critically ill patients. There are very few studies concerned with pain, anxiety and agitation and the consequences in older critically ill patients. The overall aim of this study is to identify how an ICU stay influences an older person's experiences later in life. More specific, this study has the following objectives: (1) to explore the relationship between pain, anxiety and agitation during ICU stays and experiences of the same symptoms in later life; and (2) to explore the associations between pain, anxiety and agitation experienced during ICU stays and their effect on subsequent health-related quality of life, use of the health care system (readmissions, doctor visits, rehabilitation, medication use), living situation, and survival after discharge and at 6 and 12 months of follow-up.
\end{abstract}

Methods/Design: A prospective, longitudinal study will be used for this study. A total of 150 older critically ill patients in the ICU will participate (ICU group). Pain, anxiety, agitation, morbidity, mortality, use of the health care system, and health-related quality of life will be measured at 3 intervals after a baseline assessment. Baseline measurements will be taken 48 hours after ICU admission and one week thereafter. Follow-up measurements will take place 6 months and 12 months after discharge from the ICU. To be able to interpret trends in scores on outcome variables in the ICU group, a comparison group of 150 participants, matched by age and gender, recruited from the Swiss population, will be interviewed at the same intervals as the ICU group.

Discussion: Little research has focused on long term consequences after ICU admission in older critically ill patients. The present study is specifically focussing on long term consequences of stress factors experienced during ICU admission.

Trial Registration: ISRCTN52754370

\section{Background}

Modern methods in intensive care medicine often enable the survival of older critically ill patients. The short-term outcomes for patients treated in intensive care units (ICUs), such as survival to hospital discharge, are well documented. However, relatively little is known about subsequent long-term outcomes [1]. It is generally recognized that survival alone is not the only important

\footnotetext{
* Correspondence: Marie-Madlen.Jeitziner@insel.ch

'Department of Intensive Care Medicine, Inselspital/Bern University Hospital and University of Bern, Bern, Switzerland

Full list of author information is available at the end of the article
}

outcome following an ICU stay. Various stress factors experienced in the ICU and the severity of illness or injury have long-term consequences [2-4]. Over the long term, discomfort experienced in the ICU and stressful memories of an ICU stay have been associated with the development of acute posttraumatic stress disorderrelated syndromes, anxiety, depression, and impaired health-related quality of life (HR-QOL) [5-9]. For some patients these symptoms are chronic and cause lasting personality changes. Other studies focus on outcomes such as functional status, ability to live at home, influence on the social network, and the burden on the family, all 
of which can, at times, be more important than the length of survival [10-12]. Recent research has indicated that there may be significant cognitive and emotional dysfunction following critical illness [13-15]. Another study shows that survivors of critical illnesses have increased health care system needs. Continuing hospital care, and/or rehabilitation, community support services or other healthcare services after the ICU stay were needed. In addition, there was an increase in the use of medication and of doctor visits [16]. An increasing proportion of critically ill patients are aged (65 years and older). Older patients with severe injuries are at risk of poor outcome [17]. Mortality rates are almost 22\% in older surgical patients [18], and yet age alone does not appear to be a reliable predictor of outcome after ICU admission $[19,20]$. Older patients express preferences for longer life under compromised health conditions more frequently than healthy persons [21]. Until now, few studies have examined long-term outcomes after ICU admissions in older critically ill patients [17,22,23]. Pain, anxiety and agitation are important stress factors for many critically ill patients, yet these symptoms are difficult to distinguish from one another. Pain, anxiety and agitation can have consequences for the health-related quality of life [5]. In addition, pain, anxiety, and agitation, and their consequences for long-term outcomes, have rarely been examined in older critically ill patients in the ICU [24-26]. In contrast to other studies [22,23], the present study examines the relationship between the ICU stay and post-hospital pain, anxiety and agitation in older critically ill patients, and addresses whether acute experiences in the ICU can cause more serious chronic conditions after discharge. This article describes a longitudinal study in which older critically ill patients are followed one year after their discharge from the hospital. Under investigation were their pain experiences, levels of anxiety and agitation, health-related quality of life, and use of the health care system, in order to detect relationships between these main outcomes and their ICU experiences.

\section{Study Aims}

The overall aim of this study is to identify how an ICU stay influences an older person's experiences later in life. The study addresses the following research questions: (1) Does an ICU stay influence the pain, anxiety, and agitation experienced by older critically ill patients after discharge, and at 6- and 12-month follow-up? (2) Do the pain, anxiety and agitation experienced by older critically ill patients during an ICU stay affect their experiences of these symptoms after discharge, and at 6and 12-month follow-up? (3) Does an ICU stay affect the health-related quality of life (HR-QOL) of older critically ill patients after discharge, and at 6-and 12month follow-up? (4) What is the relation between the
ICU stay and subsequent use of the health care system (readmissions, general practitioner visits, rehabilitation, length of hospital stay), medication use, living situation, and survival as experienced by older critically ill patients after discharge, and at 6- and 12-month follow-up?

\section{Methods/Design \\ Design}

A prospective longitudinal study will be conducted in older critically ill patients admitted to the ICU. Data will be collected over a period of two years at the following intervals: during ICU admission and 1 week, 6 months and 12 months after hospital discharge. A flow chart of the study is presented in Figure 1.

\section{Participants and Setting}

The study will be conducted in the interdisciplinary ICU of a Swiss university hospital, where approximately 4000 patients with surgical procedures, illnesses, and trauma are treated each year, as well as at 12 follow-up clinics. From this ICU, 150 older critically ill patients (age 65 years and older) will be recruited, to be followed until 1 year after discharge from the hospital (the ICU group). A sample of 100 patients will be needed, based on a power analysis; with a 95\% confidence interval for an estimated prevalence of pain between $0.30-0.50$ and a total of 0.20 , a sample size of 81-96 is needed. In order to ensure a large enough sample, and to counteract the potential loss of participants through mortality, relocation, attrition, or other problems, an additional 50 participants will be recruited (150 total). In order to be able to interpret trends in scores in the ICU group for the outcome variables pain, anxiety, agitation, $H R Q O L$, use of the health care system (readmissions, GP visits, rehabilitation, length of hospital stay), medication use, living situation, and survival, we decided to collect similar data in a comparison group. Participants of the comparison group are a convenience sample of older people from the Swiss population, who have not been admitted to an ICU for the last 15 years. Through matching of age and gender, an attempt is made to increase the comparability of the groups at baseline.

\section{Inclusion and exclusion criteria}

To participate in this study, the participants must have a minimum age of 65 years, have had an ICU stay of at least 48 hours (ICU group) or no stay for the last 15 years (comparison group), be able to speak and read either German or French, and live in Switzerland. Excluded were participants because of temporary tracheostomies, chronic mechanical ventilation, illnessrelated cognitive impairment (dementia), or psychotic illnesses including delusions and changes in mental state, and potentially terminal illnesses such as lung or heart diseases and cancer. 


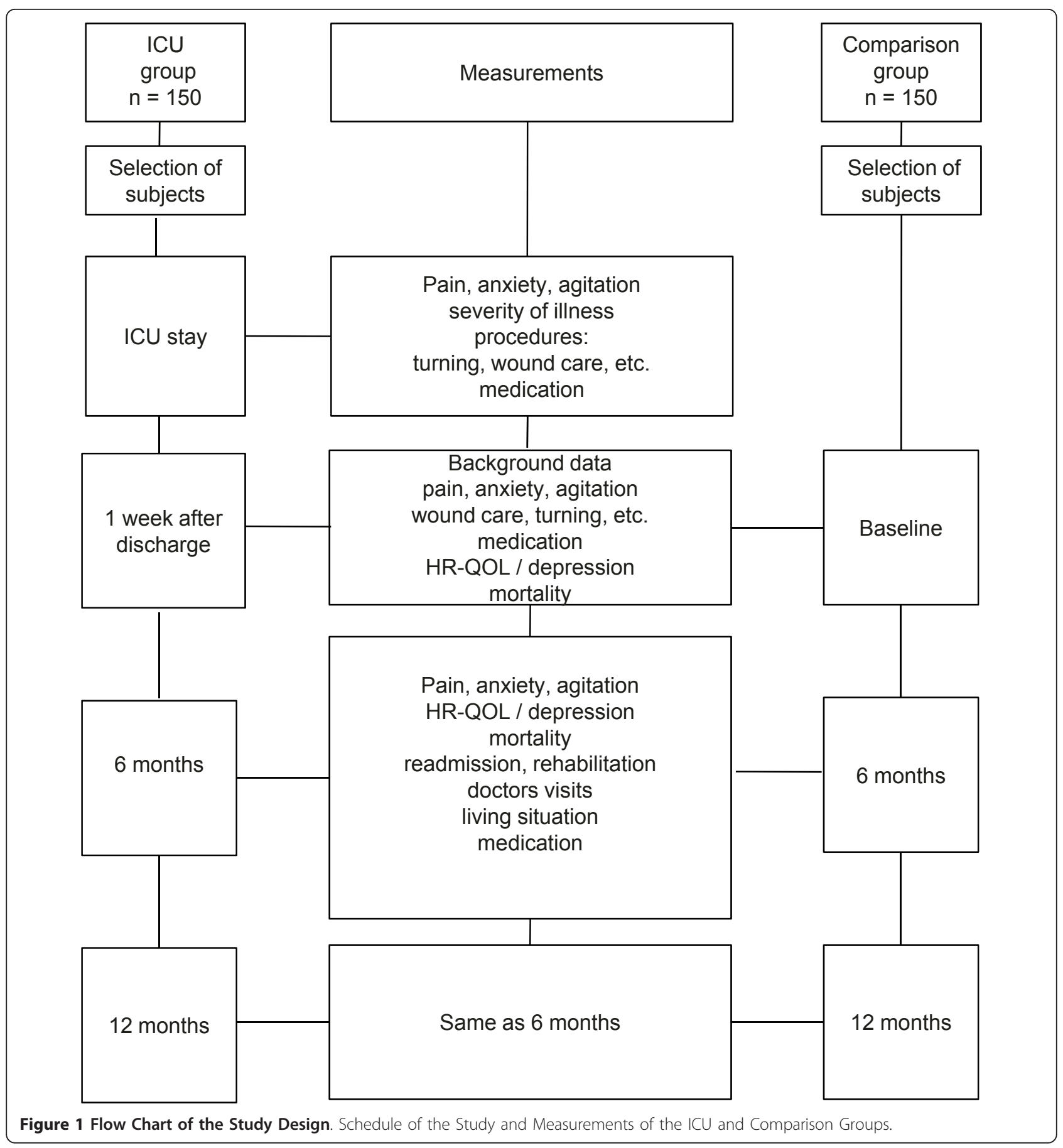

\section{Measurements}

\section{Background data}

Demographic data include age, gender and marital status. Furthermore, health-related data including Activities of Daily Living (ADL) and co-morbidities will be collected at baseline for all participants. The severity of the patient's condition will be determined using the Acute Physiology and Chronic Health Evaluation (APACHE II) and the Simplified Acute Physiology Score (SAPS II) [27].
The performance of ADL will be measured using items querying the need for assistance with daily activities (home health care, home food delivery, residence in a retirement home or nursing home) and various qualityof-life dimensions such as physical function, physical role function, vitality and social role function (Short Form 36 Health Survey [SF-36]). A scale developed for this study will be used to assess the need for assistance with daily activities (completely dependent; needs support by 
caregivers and special medical equipment; needs caregivers; independent with medical equipment; completely independent). Co-morbidities will be measured using the International Classification of Diseases (ICD), Version 10 [28].

\section{Pain, anxiety and agitation during an ICU stay}

During the ICU stay, pain, anxiety and agitation will be measured in the ICU group. In patients unable to express pain themselves verbally, pain intensity will be measured using a behavioural pain scale employing three behavioural parameters-mimic, body movement, and muscle tone. The intensity of the behavioural parameters will be assessed on the basis of a four-point Likert scale: each characteristic will be rated as weak or absent, moderately severe, severe, or very severe. The validity of the scale has been determined to be adequate, and its interrater reliability is high (kappa value 0.80) (Jeitziner MM. et al. Assessment of pain in sedated and mechanically ventilated patients: an observational study, submitted). Furthermore, potentially painful procedures will be recorded. The painful procedures include: intratracheal suctioning, dressing changes, repositioning in bed, and insertion of a central venous catheter [29]. Anxiety will be assessed using a numeric rating scale $(0-10)(0=$ no anxiety to $10=$ worst possible anxiety) [30]. Agitation during the ICU stay will be measured using the German version of the Richmond Agitation-Sedation Scale (RASS), which has 10 levels, ranging from -5: unarousable (no response) to +4 : combative (danger to staff). This scale has proven reliable for the assessment of critically ill patients in the ICU, with strong interrater reliability and criterion, construct, and face validity [31,32]. The Confusion Assessment Method for the ICU (CAM-ICU) will be used to assess delirium in the ICU [33], as well as general cognitive abilities, focusing on the following factors: a) acute onset or fluctuating course, b) inattention, c) disorganized thinking, and d) altered level of consciousness. This scale has been proven reliable and valid, with an interrater reliability kappa value of 0.96 . Its sensitivity was $100 \%$ and $93 \%$, with $98 \%$ and $100 \%$ specificity [34].

\section{Outcome indicators after discharge}

In line with the study aims, the following outcome indicators will be measured in both the ICU group and the comparison group: (1) pain, anxiety and agitation, (2) HRQOL and (3) use of the health care system (readmissions, general practitioner visits, rehabilitation, length of hospital stay), medication use, living situation and survival. Pain intensity will be measured with a numeric scale (NRS) $(0=$ no pain to $10=$ worst possible pain) $[29,30]$, and pain frequency with a Likert-type scale (never, seldom, occasionally, often, always). Anxiety will be assessed using a numeric rating scale (0-10) and the Hospital Anxiety and Depression Scale (HADS-D), which uses two subscales-an anxiety scale (HADS-A) and a depression scale (HADS-D). Internal consistency (Cronbach's alpha) is 0.80 for HADS-A and 0.81 for HADS-D. The testretest reliability shows the correlations $\mathrm{r}=0.81$ for HADS-A and $r=0.89$ for HADS-D [35]. Agitation will be measured using the Confusion Assessment Method (CAM). The German or French Short Form of the Confusion Assessment Method (CAM) [36], including a telephone version for the 6- and 12-month follow-ups [37], will be used for all participants. The inter-observer reliability of the CAM is high (kappa $=0.81-1.0)$ [38]. Healthrelated quality of life (HR-QOL) will be assessed using the component scores of the Short Form 36 Health Survey (SF-36). As a comprehensive, generic, 36-item instrument, the SF-36 concentrates on the subjective evaluation of health: 1) physical function, 2) physical role function, 3) bodily pain, 4) general health perceptions, 5) vitality, 6) social role function, 7) emotional role function, and 8) mental health. The items vary from yes/no questions to those offering 6 levels of choice. All subscales have been adapted to yield assessment values between 0 and 100. The health care system assessment will include the number, cause, and length of hospital admissions and stays using APACHE-Diagnosis nonoperative and operative diagnoses (1) cardiovascular, 2) respiratory, 3) gastrointestinal, 4) neurological, 5) sepsis, 6) trauma, 7) metabolic, 8) haematological, 9) other, 10) cardiologic surgery, 11) respiratory surgery, etc., the number and the length of rehabilitation periods (location, length, ambulatory, stationary, discharge location) and the number of GP visits. Medication therapy, and mortality incidence, will be collected from all subjects in the ICU and comparison groups over the course of the study. Medication therapy includes all sedative, analgesic, antipsychotic, psychotropic, steroidal, and vasoactive medications. The cumulative amount of medication will be recorded. Mortality incidence will be determined based on survival rates. For all instruments, French and German versions will be available. Translation of the SF-36 into German and French was done according to the Translation Protocols of the International Quality of Life Assessment Group [39,40]. The SF-36 Health Survey and the HADS-D have been used in a range of intensive care-related studies $[5,41,42]$. An overview of all measurements is summarized in Tables 1 and 2.

\section{Procedure}

Background data will be gathered via medical records and questionnaires. Medical and nursing staff will gather daily routine data regarding pain, anxiety, and agitation, along with any other information relevant to usual care in the ICU. Collection of data concerning pain, anxiety and 
Table 1 Measurements during ICU stay

\begin{tabular}{lll}
\hline Variables & Instruments & Sources \\
\hline Pain (intensity, frequency) & Behavioural scale & PDMS/Q \\
\hline Agitation (intensity, frequency) & RASS, CAM-ICU & PDMS/Q \\
\hline Reasons for ICU admission (cause) & $\begin{array}{l}\text { APACHE: } \\
\text { diagnosis at } \\
\text { admission }\end{array}$ & MR/Q \\
\hline Severity of illness & APACHE II, SAPS II & PDMS
\end{tabular}

Note: RASS = Richmond Agitation-Sedation Scale. CAM-ICU = Confusion Assessment Method for the ICU. APACHE = Acute Physiology and Chronic Health Evaluation. SAPS $=$ Simplified Acute Physiology Score. PDMS $=$ Patient Data Management System. $M R=$ Medical record. $Q=$ Questionnaire.

agitation will be carried out by the staff who regularly care for the patients. For this study these caregivers have received special training. Data about the outcome indicators will be collected using questionnaires 1 week, 6 months and 12 months after discharge. It should be emphasized that participants in the ICU group will be asked one week after discharge to make an assessment of both their current HR-QOL and their HR-QOL, pain, anxiety and agitation intensity, before admission to the ICU. One week after ICU discharge, patients in the ICU group will be contacted and interviewed. The interviews will be carried out only if the patients are physically and psychologically fit to be interviewed. If necessary, help will be provided in filling out the questionnaire. All data will be collected using face-to-face (baseline) and telephone (follow-up) interviews and will be collected by 4 trained interviewers. The baseline interviews with all critically ill patients will take place in the hospital. All other interviews for both groups will take place by telephone. The SF36 and HADS-D will be mailed to all participants. In order for them to prepare themselves for the interview, both groups will be informed of the general nature of the questions ahead of time. Because unanswered questions would affect the evaluation of the questionnaires, an interviewer will check to ensure that all questions have been answered, and follow up in cases where information is lacking. If questionnaires are not returned, reminders will be sent to the participants.

\section{Ethical Considerations}

The study protocol was approved by the Cantonal Ethics Commission of Bern. For the patient interviews during the first week ( 5 to 10 days) after the ICU stay, patients will be contacted, comprehensively informed about the study-verbally and in writing-and invited to participate. The participants in the comparison group will receive the same information. Study participants agree to participate via a written informed consent form. To ensure confidentiality, all data will be coded, and all personal data will be documented, archived, and analyzed anonymously, making it impossible to determine the identity of the individual participants.

\section{Data Analysis}

The statistical analysis will be performed using the $\mathrm{R}$ Project for Statistical Computing. Descriptive statistical analyses (mean, median, interquartile range) will be used to describe and characterize the data. To indicate the strength and direction of relationships between variables, Spearman's rank correlation coefficient for ordinal data and Pearson's product-moment coefficient will be conducted, depending on measurement levels and data dispersion. The Mann-Whitney U Test will be used for continuous data when comparing groups, and random effects models will be used for the longitudinal data. Attrition (i.e., missing data) during the follow-up will be reported.

\section{Discussion}

This article presents the design of a prospective longitudinal study investigating the associations between admission to the ICU and pain, anxiety, agitation, healthrelated quality of life, and use of the health care system in later life. Previous longitudinal studies have examined ICU patients' health-related quality of life [4,7-9] or traumatic memories of postoperative treatment [2,5]. The present study specifically assesses situations involving pain, anxiety and agitation in older patients, as well as their consequences. These symptoms can influence the long-term outcomes of older critically ill patients. The

Table 2 Measurements in the ICU group and the comparison group (Follow-up)

\begin{tabular}{|c|c|c|c|c|}
\hline Variables & Instruments & Time of Measurement & & \\
\hline & & Baseline/1 week after discharge ICU & 6 months & 12 months \\
\hline Pain (intensity, frequency) & NRS & Q & Q & Q \\
\hline Anxiety (intensity, frequency) & NRS, HADS-D & Q & Q & Q \\
\hline Agitation (intensity, frequency) & CAM & Q & Q & Q \\
\hline Mortality & Survival: Yes/No & Q & Q & Q \\
\hline Morbidity & International classification of diseases, version 10 & $\mathrm{MR} / \mathrm{Q}$ & $\mathrm{MR} / \mathrm{Q}$ & $\mathrm{MR} / \mathrm{Q}$ \\
\hline Quality of life (HR-QOL) ${ }^{1}$ & SF-36 & Q & Q & $\mathrm{Q}$ \\
\hline
\end{tabular}

Note: NRS = Numeric rating scale. HADS-D = Hospital Anxiety and Depression Scale. CAM = Confusion Assessment Method. SF-36 = Short Form 36 Health Survey. $\mathrm{HR}-\mathrm{QOL}=$ Health-related quality of life. $\mathrm{MR}=$ Medical record. $\mathrm{Q}=$ Questionnaire. 
study will be conducted over a period of two years. Data on health-related quality of life are time dependent and related to the life situation of the participant. Changes that take place during the follow-ups, such as modifications in therapy or accidents, were integrated into the analysis, based on the various measurement techniques. The instruments used for the study represent a limitation.

Various studies have attempted to explain ICU stayrelated variables by using identical generic instruments to compare critically ill patients' health-related quality of life with that of comparison groups from the general population $[4,9,41,42]$.

Apparently, illness-specific influences on health-related quality of life are not identified by these generic instruments. Various studies assessed HR-QOL with a variety of instruments $[19,43]$ In addition, the effort required for older people to fill out multiple questionnaires is not negligible. Some studies on critically ill patients have questioned the patients' families regarding their health-related quality of life $[44,45]$. However, due to the subjective nature of quality of life, the current study uses only interview and questionnaire data provided by the patients themselves, in order to more accurately describe the patients' own perception of their ICU stay. Until now, little research has focused on the short- and long-term consequences of pain, anxiety, and agitation in older patients, including the effect on the patients' use of the health care system. Because inadequate pain assessment and management may needlessly increase hospital readmissions and the use of the health care system, this topic should be of broad interest. This study will provide the first data on the situation in Switzerland.

\section{Acknowledgements}

We thank Dr. Stephen O'Connor, Dr. Erik van Rossum, and Ottilia Rohrer, RN, for their valuable feedback in the preparation of this manuscript. We would like to thank Jeannie Wurz and Linda Bolzern for carefully editing the manuscript.

\section{Author details}

${ }^{1}$ Department of Intensive Care Medicine, Inselspital/Bern University Hospital and University of Bern, Bern, Switzerland. ${ }^{2}$ Institute of Applied Nursing Science, University of St. Gallen, Switzerland. ${ }^{3}$ Cantonal Hospital Aarau, Aarau, Switzerland. ${ }^{4}$ Maastricht University, School for Public Health and Primary Care, Department of Health Care and Nursing Science, Maastricht, Netherlands.

\section{Authors' contributions}

All authors contributed to the preparation of the manuscript, and participated in the research. All authors read and approved the final manuscript.

\section{Competing interests}

The authors declare that they have no competing interests.

Received: 21 March 2011 Accepted: 2 September 2011 Published: 2 September 2011
References

1. Williams TA, Dobb GJ, Finn JC, Webb SA: Long-term survival from intensive care: a review. Intensive Care Med 2005, 31:1306-1315.

2. Novaes MA, Aronovich A, Ferraz MB, Knobel E: Stressors in ICU: patients' evaluation. Intensive Care Med 1997, 23:1282-1285.

3. Williams TA, Dobb GJ, Finn JC, Knuiman MW, Geelhoed E, Lee KY, Webb SA: Determinants of long-term survival after intensive care. Crit Care Med 2008, 36:1523-1530.

4. Schelling $G$, Richter M, Roozendaal B, Rotenhäusler HB, Krauseneck T, Stoll C, Nollert G, Schmidt M, Kapfhammer HP: Exposure to high stress in the intensive care unit may have negative effects on health-related quality of life outcomes after cardiac surgery. Crit Care Med 2003, 31:1971-1980.

5. Jones C, Griffiths RD, Humphris G, Skirrow PM: Memory, delusions, and the development of acute posttraumatic stress disorder-related symptoms after intensive care. Crit Care Med 2001, 29:573-580.

6. Rattray JE, Johnston M, Wildsmith JA: Predictors of emotional outcomes of intensive care. Anaesthesia 2005, 60:1085-1092.

7. Granja C, Lopes A, Moreira S, Dias C, Costa-Pereira A, Carneiro A: Patients' recollections of experiences in the intensive care unit may affect their quality of life. Crit Care 2005, 9:R96-109.

8. Ulvik A, Kvale R, Wentzel-Larsen T, Flaatten H: Quality of life 2-7 years after major trauma. Acta Anaesthesiol Scand 2008, 52:195-201.

9. Hofhuis JG, Spronk PE, van Stel HF, Schrijvers GJ, Rommes JH, Bakker J: The impact of critical illness on perceived health-related quality of life during ICU treatment, hospital stay, and after hospital discharge: a longterm follow-up study. Chest 2008, 133:377-385.

10. Lee BO, Chaboyer W, Wallis M: Predictors of health-related quality of life 3 months after traumatic injury. J Nurs Scholarsh 2008, 40:83-90.

11. Richter JC, Pajonk FG, Waydhas C, Bregenzer T: Lebensqualität nach chirurgischer Langzeitintensivtherapie. Anästhesist 2000, 49:822-828.

12. Chaboyer W, Grace J: Following the path of ICU survivors: a qualityimprovement activity. Nurs Crit Care 2003, 8:149-155.

13. Jackson JC, Girard TD, Gordon SM, Thompson JL, Shintani AK, Thomason JW, Pun BT, Canonico AE, Dunn JG, Bernard GR, Dittus RS, Ely EW: Long-term cognitive and psychological outcomes in the awakening and breathing controlled trial. Am J Respir Crit Care Med 2010, 182:183-191.

14. Jackson JC, Obremskey W, Bauer R, Greevy R, Cotton BA, Anderson V, Song $Y$, Ely EW: Long-term cognitive, emotional, and functional outcomes in trauma intensive care unit survivors without intracranial hemorrhage. J Trauma 2007, 62:80-88.

15. Rattray J, Crocker C, Jones M, Connaghan J: Patients' perceptions of and emotional outcome after intensive care: results from a multicentre study. Nurs Crit Care 2010, 15:86-93.

16. Williams TA, Leslie GD, Brearley L, Dobb GJ: Healthcare utilisation among patients discharged from hospital after intensive care. Anaesth Intensive Care 2010, 38:732-739.

17. Aitken LM, Burmeister E, Lang J, Chaboyer W, Richmond TS: Characteristics and outcomes of injured older adults after hospital admission. J Am Geriatr Soc 2010, 58:442-449.

18. Arenal JJ, Bengoechea-Beeby M: Mortality associated with emergency abdominal surgery in the elderly. Can J Surg 2003, 46:111-116.

19. Chelluri L, Pinsky MR, Donahoe MP, Grenvik A: Long-term outcome of critically ill elderly patients requiring intensive care. JAMA 1993, 269:3119-3123.

20. Kleinpell RM, Ferrans CE: Factors influencing intensive care unit survival for critically ill elderly patients. Heart Lung 1998, 27:337-343.

21. Winter L, Lawton MP, Ruckdeschel K: Preferences for prolonging life: a prospect theory approach. Int J Aging Hum Dev 2003, 56:155-170.

22. Noseworthy TW, Gibney RT, Konopad E, Shustack A, Stollery D, Johnston R, Grace M: One-year outcome of elderly and young patients admitted to intensive care units. Crit Care Med 1993, 21:687-691.

23. Kaarlola A, Tallgren M, Pettilä V: Long-term survival, quality of life, and quality-adjusted life-years among critically ill elderly patients. Crit Care Med 2006, 34:2120-2126.

24. Valdix SW, Puntillo KA: Pain, pain relief and accuracy of their recall after cardiac surgery. Prog Cardiovasc Nurs 1995, 10:3-11.

25. Moser DK, Dracup K, McKinley S, Yamasaki K, Kim CJ, Riegel B, Ball C, Doering LV, An K, Barnett M: An international perspective on gender 
differences in anxiety early after acute myocardial infarction. Psychosom Med 2003, 65:511-516.

26. Inouye SK: The dilemma of delirium: clinical and research controversies regarding diagnosis and evaluation of delirium in hospitalized elderly medical patients. Am J Med 1994, 97:278-288.

27. Janssens U, Jordan A, Graf C, Graf J, Grenner H, Hanrath P: Vergleich von APACHE II, SAPS und TISS im täglichen Einsatz bei Patienten einer kardiologischen Intensivstation. Intensivmed 2000, 37:31-43.

28. Schweizerische Eidgenossenschaft: Statistik Schweiz. Normenklaturen 2011, Internationale Klassifikation der Krankenheiten (ICD-10). [http:// www.bfs.admin.ch].

29. Puntillo KA, Morris AB, Thompson CL, Stanik-Hutt J, White CA, Wild LR: Pain behaviors observed during six common procedures: results from Thunder Project II. Crit Care Med 2004, 32:421-427.

30. Li DT, Puntillo K: A pilot study on coexisting symptoms in intensive care patients. Appl Nurs Res 2006, 19:216-219.

31. Sessler CN, Gosnell MS, Grap MJ, Brophy GM, O'Neal PV, Keane KA, Tesoro EP, Elswick RK: The Richmond Agitation-Sedation Scale: validity and reliability in adult intensive care unit patients. Am J Respir Crit Care Med 2002, 166:1338-1344.

32. Ely EW, Truman B, Shintani A, Thomason JW, Wheeler AP, Gordon S, Francis J, Speroff T, Gautam S, Margolin R, Sessler CN, Dittus RS, Bernard GR: Monitoring sedation status over time in ICU patients: reliability and validity of the Richmond Agitation-Sedation Scale (RASS). JAMA 2003, 289:2983-2991.

33. Putensen C, Guenther U: Die Confusion Assessment Method (CAM) für Intensivstationen (CAM-ICU). Übungsleitfaden. Vanderbilt University. 2002 [http://www.mc.vanderbilt.edu/icudelirium/docs/ CAM_ICU_training_German.pdf].

34. Ely EW, Inouye SK, Bernard GR, Gordon S, Francis J, May L, Truman B, Speroff T, Gautam S, Margolin R, Hart RP, Dittus R: Delirium in mechanically ventilated patients: validity and reliability of the confusion assessment method for the intensive care unit (CAM-ICU). JAMA 2001, 286:2703-2710.

35. Herrmann Ch, Buss U, Snaith RP: HADS-D: Ein Fragebogen zur Erfassung von Angst und Depressivität in der somatischen Medizin. Testdokumentation und Handanweisung Bern: Hans Huber; 1995.

36. Bickel H: Deutsche Version der Confusion Assessment Method (CAM) zur Diagnose des Delirs. Psychosom Konsiliarpsychiatr 2007, 1:224-228.

37. Marcantonio ER, Michaels M, Resnick NM: Diagnosing delirium by telephone. J Gen Intern Med 1998, 13:621-623.

38. Inouye SK, van Dyck CH, Alessi CA, Balkin S, Siegal AP, Horwitz Rl: Clarifying confusion: the confusion assessment method. A new method for detection of delirium. Ann Intern Med 1990, 113:941-948.

39. Bullinger M, Kirchberger I, Ware J: Der deutsche SF-36 Health Survey. Übersetzung und psychometrische Testung eines krankheitsübergreifenden Instruments zur Erfassung der gesundheitsbezogenen Lebensqualität. Zeitschrift für Gesundheitswissenschaften 1995, 1:21-36.

40. Bullinger M: Erfassung der gesundheitsbezogenen Lebensqualität mit dem SF-36-Health Survey. Bundesgesundheitsblatt - Gesundheitsforschung Gesundheitsschutz 2000, 43:190-197.

41. Ringdal M, Plos K, Lundberg D, Johansson L, Bergbom I: Outcome after injury: memories, health-related quality of life, anxiety, and symptoms of depression after intensive care. J Trauma 2009, 66:1226-1233.

42. Boyle M, Murgo M, Adamson H, Gill J, Elliott D, Crawford M: The effect of chronic pain on health related quality of life amongst intensive care survivors. Aust Crit Care 2004, 17:104-106, 108-113.

43. Montuclard L, Garrouste-Orgeas M, Timsit JF, Misset B, De Jonghe B, Carlet J: Outcome, functional autonomy, and quality of life of elderly patients with a long-term intensive care unit stay. Crit Care Med 2000, 28:3389-3395.

44. de Rooij SE, Govers AC, Korevaar JC, Giesbers AW, Levi M, de Jonge E: Cognitive, functional, and quality-of-life outcomes of patients aged 80 and older who survived at least 1 year after planned or unplanned surgery or medical intensive care treatment. J Am Geriatr Soc 2008, 56:816-822.

45. Hofhuis J, Hautvast JL, Schrijvers AJ, Bakker J: Quality of life on admission to the intensive care: can we query the relatives? Intensive Care Med 2003, 29:974-979.

\section{Pre-publication history}

The pre-publication history for this paper can be accessed here: http://www.biomedcentral.com/1471-2318/11/52/prepub

doi:10.1186/1471-2318-11-52

Cite this article as: Jeitziner et al:: Long-term consequences of an intensive care unit stay in older critically ill patients: design of a longitudinal study. BMC Geriatrics 2011 11:52.

\section{Submit your next manuscript to BioMed Central and take full advantage of:}

- Convenient online submission

- Thorough peer review

- No space constraints or color figure charges

- Immediate publication on acceptance

- Inclusion in PubMed, CAS, Scopus and Google Scholar

- Research which is freely available for redistribution

Submit your manuscript at www.biomedcentral.com/submit
Biomed Central 